\title{
Rhodophyta de ambientes lóticos de Unidades de Conservação da região Sul do Brasil
}

\author{
Ciro Cesar Zanini Branco ${ }^{1,4}$, Thais Antunes Riolfi, Cleto Kaveski Peres ${ }^{2}$ \& Orlando Necchi Júnior ${ }^{3}$ \\ ${ }^{1}$ Universidade Estadual Paulista - UNESP, FCL, Assis, Av. Dom Antônio, 2100, \\ Parque Universitário, CEP 19806-900, Assis, SP, Brasil \\ ${ }^{2}$ Universidade Federal da Integração Latino-Americana - UNILA, \\ Av. Tancredo Neves, 6731, Parque Tecnológico Itaipu, Bloco 4, Foz do Iguaçu, PR, Brasil \\ ${ }^{3}$ Departamento de Zoologia e Botânica, Universidade Estadual Paulista - UNESP, \\ Rua Cristóvão Colombo, 2265, CEP 15054-000, São José do Rio Preto, SP, Brasil \\ ${ }^{4}$ Autor para correspondência: Ciro Cesar Zanini Branco, e-mail: czbranco@assis.unesp.br
}

BRANCO, C.C.Z., RIOLFI, T.A., PERES, C.K. \& NECCHI JÚNIOR, O. Rhodophyta from streams of Conservation Units in Southern Brazil. Biota Neotrop. 11(3): http://www.biotaneotropica.org.br/v11n3/en/ abstract?inventory + bn03811032011

\begin{abstract}
Species of Rhodophyta from 10 Conservation Units from the south region of Brazil were surveyed. The samplings were carried out in 105 stream reaches, consisting of $10 \mathrm{~m}$ length transects. The floristic survey involved 80 populations, representing three genera, Batrachospermum, Kumanoa and Hildenbrandia plus the 'Chantransia' stages. Batrachospermum was represented by five species (B. arcuatum Kylin, B. atrum (Hudson) Harvey, B. helminthosum Bory, B. keratophytum Bory and B. puiggarianum Grunow in Wittrock \& Nordstedt). The genus Kumanoa was represented by $K$. abilii (Reis) Necchi Júnior \& Vis and K. ambigua (Montagne) Entwisle et al., while Hildenbrandia only by H. angolensis W.West \& G.S.West. Our results confirm Batachospermum as the best represented genus, in terms of species number, among freshwater Rhdophyta. B. arcuatum was a new record for the south region of Brazil, thus extending its austral distribution range.

Keywords: red algae, taxonomic survey, lotic ecosystems, subtropical region, Kumanoa.
\end{abstract}

BRANCO, C.C.Z., RIOLFI, T.A., PERES, C.K. \& NECCHI JÚNIOR, O. Rhodophyta de ambientes lóticos de Unidades de Conservação da região Sul do Brasil. Biota Neotrop. 11(3): http://www.biotaneotropica.org. br/v11n3/pt/abstract?inventory + bn03811032011

Resumo: Espécies de Rhodophyta de 10 Unidades de Conservação da região Sul do Brasil foram investigadas. As amostragens foram conduzidas em 105 segmentos de riachos consistindo em transeções de $10 \mathrm{~m}$ de comprimento. O levantamento florístico resultou em 80 populações representando três gêneros, Batrachospermum, Kumanoa e Hildenbrandia, além do estágios 'Chantransia'. Batrachospermum foi representado por cinco espécies (B. arcuatum Kylin, B. atrum (Hudson) Harvey, B. helminthosum Bory, B. keratophytum Bory, B. puiggarianum Grunow in Wittrock \& Nordstedt). O gênero Kumanoa foi representado por K. abilii (Reis) Necchi Júnior \& Vis e K. ambigua (Montagne) Entwisle et al., enquanto Hildenbrandia exclusivamente por H. angolensis W. West \& G.S. West. Nossos resultados confirmam Batachospermum como o gênero melhor representado, em termos de número de espécies, entre as Rhdophyta de água doce. Batrachospermum arcuatum foi registrado pela primeira vez na região Sul do Brasil, ampliando assim, o limite austral de sua distribuição.

Palavras-chave: algas vermelhas, levantamento taxonômico, ecossistemas lóticos, região subtropical, Kumanoa. 


\section{Introdução}

As Rhodophyta de águas continentais compreendem um grupo de aproximadamente 20 gêneros e 150 espécies (Graham \& Wilcox 2000) que, em geral, habitam ecossistemas lóticos e possuem crescimento macroscópico evidente e morfologia variável. Nas últimas décadas um crescente corpo de informações taxonômicas sobre este grupo de algas tem sido produzido tanto no Brasil (Necchi Júnior 1986, 1987a, 1989, 1990a, b, 1991, 1993, Necchi Júnior et al. 2010a, b) como em outras regiões do mundo (Entwisle \& Kraft 1984, Kumano \& Necchi Júnior 1990, Kumano 1993, Sheath et al. 1994a, b, c, 1995, Vis et al. 1995, 2006, Necchi Júnior et al. 2007). Na região Sul do Brasil, porém, registros de algas vermelhas de rios e riachos são encontrados na literatura ficológica especializada apenas sob a forma de citações esparsas entre os representantes das comunidades de macroalgas em estudos de cunho generalista (Branco et al. 2008, 2009, Krupek et al. 2008, Peres et al. 2008) ou em investigações específicas do gênero Batrachospermum (Necchi Júnior 1990a).

Recentemente, as Rhodophyta continentais vêm passando por importantes mudanças sistemáticas em função de estudos filogenéticos, particularmente aqueles baseados em dados macromoleculares (Entwisle et al. 2009, Necchi Júnior et al. 2010b). Entre estas modificações, uma das mais significativas foi a proposição de fundação de Kumanoa Entwisle et al., a partir da elevação da seção Contorta Skuja de Batrachospermum Roth, para o nível gênero. Assim, o objetivo do presente estudo foi realizar o levantamento taxonômico das algas vermelhas de ambientes lóticos de Unidades de Conservação (UCs) dos principais biomas da região Sul do Brasil, com base nas mais recentes propostas de classificação do grupo. Neste contexto, além de contribuir para a ampliação do conhecimento da diversidade do grupo em uma região carente destas informações, o presente trabalho também servirá de bibliografia atualizada para estudos sistemáticos e taxonômicos envolvendo estas algas.

\section{Material e Métodos}

As amostragens foram realizadas em 105 segmentos de rios/ riachos (e.g., pontos de amostragem) localizados dentro dos limites geográficos de $10 \mathrm{UCs}$ dos quatro principais biomas (Floresta Ombrófila Densa - FOD; Floresta Ombrófila Mista - FOM; Floresta Estacional, FE; Campos - C) da região Sul do Brasil (Figura 1), entre os anos de 2005 e 2008. Cada ponto de amostragem foi visitado uma vez, sempre nas épocas sazonais de menor nível de precipitação pluviométrica (e.g., final do outono ao início da primavera), período descrito como sendo o de maior diversidade e abundância de espécies de macroalgas lóticas nas regiões Sul e Sudeste do país (Branco et al. 2009).

Em cada ponto de amostragem foi estabelecida uma transeção de $10 \mathrm{~m}$ de comprimento, que foi totalmente examinada quanto à presença das espécies de algas vermelhas. Os rios/riachos variaram quanto ao tamanho, sendo amostrados desde os de $1^{\text {a }}$ ordem até os de $5^{\mathrm{a}}$ ordem, entretanto com predomínio dos ambientes lóticos de menor porte (e.g., $1^{\mathrm{a}}$ ordem a $3^{\mathrm{a}}$ ordem).

Amostras das algas coletadas nos pontos de amostragem foram preservadas em solução de formaldeído tamponado 4\% (Johansson 1982). Amostras-testemunho de cada espécie encontrada foram incorporadas aos herbários SJRP e UPCB (siglas de acordo com Holmgren \& Holmgren (1998)) em meio líquido. As observações microscópicas e as análises morfométricas foram realizadas com auxílio de microscópio trinocular Leica (modelo DM1000) e de um sistema de captura de imagens composto de câmera de vídeo Leica (modelo DFC280) acoplada a um microcomputador com o software Leica IM-50.
As identificações e discussões taxonômicas foram fundamentadas em trabalhos específicos para o grupo disponíveis na literatura (p. ex., Necchi Júnior 1987b, 1989, 1990a, b, Sheath et al. 1992, 1993a, b, 1994a, b, c, 1995, Necchi Júnior \& Zucchi 1997, Kumano 1993, 2002, Carmona-Jiménez et al. 2002, Entwisle et al. 2009).

Para cada espécie identificada são apresentadas as seguintes informações: i) descrição detalhada com base nas características morfológicas e morfométricas do material analisado; ii) ilustrações das características diacríticas; iii) comentários taxonômicos, sempre que necessário; iv) localização e distribuição na área de estudo e v) condições ambientais onde foram encontrados, incluindo os valores máximos, mínimos e médios para cada variável mensurada.

\section{Resultados}

O levantamento florístico nas UCs da região Sul do Brasil revelou a presença de oito espécies representadas pelos gêneros Batrachospermum, Hildenbrandia e Kumanoa, além dos estágios 'Chantransia', em um total de 80 populações investigadas. O gênero Batrachospermum foi representado pelas espécies $B$. arcuatum, B. atrum, B. helminthosum, B. keratophytum e B. puiggarianum. Kumanoa, por sua vez, foi representado por K. abilii e K. ambigua, enquanto o gênero Hildenbrandia, exclusivamente por $H$. angolensis. Entre as espécies reportadas, três novos registros para a região estudada foram encontrados. Neste contexto, B. arcuatum, representa um novo registro para a região sul do Brasil como um todo, ampliando assim, o limite austral de sua distribuição; B. puiggarianum foi registrado pela primeira vez para Santa Catarina e B. keratophytum para o Paraná.

\section{Descrição dos táxons inventariados na região Sul do Brasil}

\section{CLASSE FLORIDEOPHYCEAE}

\section{ORDEM BATRACHOSPERMALES}

Batrachospermum atrum (Hudson) Harvey, Man. 120. 1841.

\section{Basiônimo: Conferva atra Hudson}

Sinônimos: B. tenuissimum Bory, B. dillenii Sirodot, B. gallaei Sirodot, B. angolense W. West \& G.S. West, Sirodotia angolensis (W. West \& G.W. West) Skuja in Reis (Figuras 2-5)

Plantas dióicas, rígidas, com pouca mucilagem e ramificações irregulares e abundantes; ápice reto, verticilos densos, reduzidos, separados, pouco compactos, 123,0-448,0 um diâm. Internós com 290,0-602 um comp. Fascículos primários audouinelóides com 4-6 células; 1-3 ramificações unilaterais; células proximais cilíndricas ou ovais com 8,0-16,0 $\mu$ m comp. e 6,0-13,0 $\mu$ m diâm.; células distais esféricas ou doliformes com 7,0-12,0 $\mu \mathrm{m}$ comp. e 5,5-9,5 $\mu \mathrm{m}$ diâm. Fascículos secundários numerosos, pequenos, aderidos ao longo do internó, sempre menores que o fascículo primário; células proximais esféricas com 8,0-12,0 $\mu \mathrm{m}$ comp. e 5,5-10,5 $\mu \mathrm{m}$ diâm.; células distais ovais com 5,0-12,0 $\mu \mathrm{m}$ comp. e 4,0-9,0 $\mu \mathrm{m}$ diâm. Espermatângios esféricos, em geral terminais, nos fascículos primários ou secundários, 5,0-10,0 $\mu \mathrm{m}$ diâm. Ramos carpogoniais pequenos, em geral retos, sobre célula pericentral ou proximal; 2-4 células discóides com 4,5-10,0 $\mu \mathrm{m}$ comp. e 2,5-8,0 $\mu$ m diâm. Carpogônios simétricos, 19,5-33,5 $\mu \mathrm{m}$ comp.; tricogíneos claviformes. Carposporófitos sésseis, 1-2(-3) por verticilo, semiesféricos, com diâmetro maior que o raio de verticilo, 122,0-258,0 $\mu \mathrm{m}$ diâm. Carposporângios obovóides, ou elípticos com 10,0-15,0 $\mu \mathrm{m}$ de comp. e 7,5-10,0 $\mu \mathrm{m}$ de diâm. 


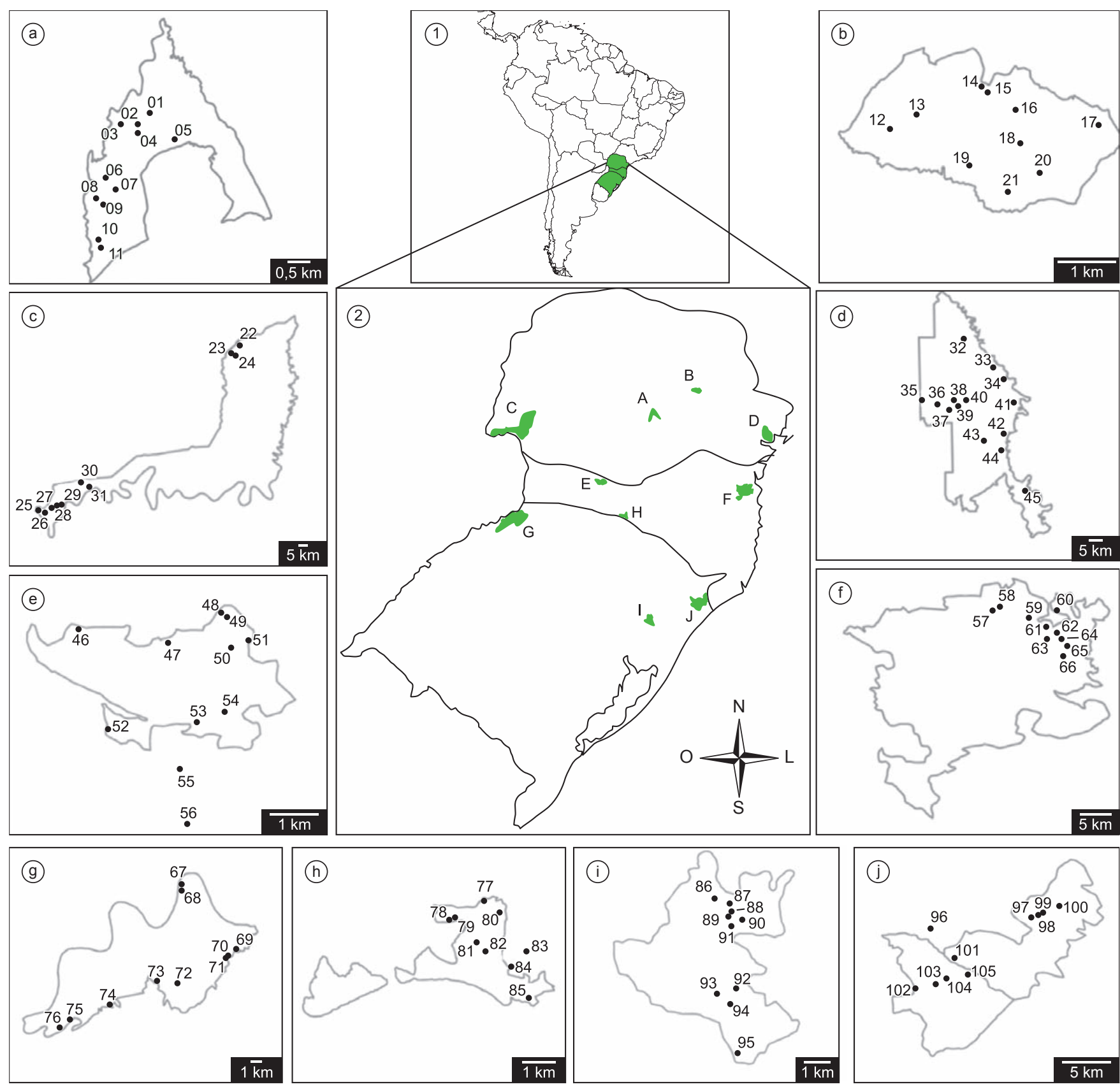

Figura 1. Mapa da região Sul do Brasil com as Unidades de Conservação (a-j) e os pontos de amostragem nos quais os espécimes foram coletados (1-105). a) Floresta Nacional de Irati; b) Parque Estadual de Vila Velha; c) Parque Nacional do Iguaçu; d) Parque Nacional Saint-Hilaire/Lange; e) Parque Estadual das Araucárias; f) Parque Nacional da Serra do Itajaí; g) Parque Florestal Estadual do Turvo; h) Parque Estadual Fritz Plaumann; i) Parque Estadual do Caracol; j) Parque Nacional de Aparados da Serra e Parque Nacional da Serra Geral.

Figure 1. Map of Southern Brazil with the Conservation Units (a-j) and the sampling sites in which the specimens were collected (1-105). a) Irati National Forest; b) Vila Velha State Park; c) Iguaçu National Park; d) Saint-Hilaire/Lange National Park; e) Araucária State Park; f) Serra do Itajaí National Park; g) Turvo State Forest Park; h) Fritz Plaumann State Park; i) Caracol State Park; j) Aparados da Serra National Park and Serra Geral National Park.

Distribuição no Sul do Brasil: pontos de amostragem 14 e 19. BRASIL. PARANÁ: Ponta Grossa, Parque Estadual de Vila Velha, riacho da Taipa, $25^{\circ} 13$ ' $17^{\prime \prime}$ S e $50^{\circ} 00^{\prime} 44^{\prime \prime} \mathrm{O}$, altitude 828 m, 03.V.2008, C.C.Z. Branco et al. s.n. (SJRP29774); idem, riacho da estrada da igreja, $25^{\circ} 14^{\prime} 41^{\prime \prime} \mathrm{S}$ e $50^{\circ} 00^{\prime} 58^{\prime \prime} \mathrm{O}$, 03.V.2008, C.C.Z. Branco et al. s.n. (SJRP29775).

Características ambientais $(\mathrm{n}=2)$ : temperatura da água $15,9-16,5^{\circ} \mathrm{C}(\bar{x}=16,2)$; condutividade específica $5-21 \mu \mathrm{S} . \mathrm{cm}^{-1}$ $(\bar{x}=13)$; pH 5,2; oxigênio dissolvido 4-4,2 mg.L $\mathrm{L}^{-1}(\bar{x}=4,1)$; turbidez 2- 8 NTU $(\bar{x}=5)$; velocidade da correnteza $92-102 \mathrm{~cm}^{-1}{ }^{-1}$ $(\bar{x}=97)$; profundidade média $33-41 \mathrm{~cm}(\bar{x}=37)$.

Considerações taxonômicas: $B$. atrum já foi registrado na região Sul do Brasil por Necchi Júnior (1990a). As características diagnósticas das populações do material estudado encaixam-se nas descrições da espécie encontradas na literatura (Necchi Júnior 1990a, Kumano 2002). 
Batrachospermum puiggarianum Grunow in Wittrock \& Nordstedt, Alg. Aqua dulc., Exsicc. No. 501. 1883.

Sinônimos: B. schwacheanum Möbius, B. nigrescens W. West \& G.S. West, Sirodotia nigrescens (W. West \& G.S. West) Skuja in Reis, B. atrum var. puiggarianum (Grunow) Necchi Júnior (Figuras 6-9)

Plantas monóicas ou dióicas, com pouca mucilagem e ramificações irregulares e abundantes; ápice reto, verticilos reduzidos, compactos, separados, 110,0-315,0 $\mu$ m diâm. Internós com 235,0-790,0 $\mu \mathrm{m}$ comp. Fascículos primários audouinelóides, curvados com (2-)3-6(-7) células; 1-3 ramificações dicotômicas; células proximais cilíndricas ou doliformes com 6,5-20,0 $\mu \mathrm{m}$ comp. e 5,0-20,0 $\mu \mathrm{m}$ diâm; células distais doliformes com 5,014,5 $\mu \mathrm{m}$ comp. e 3,0-10,5 $\mu \mathrm{m}$ diâm. Fascículos secundários numerosos, podendo alcançar o comprimento dos fascículos primários. Espermatângios esféricos ou ovais, terminais nos fascículos primários e secundários, 3,0-11,0 $\mu \mathrm{m}$ diâm. Ramos carpogoniais retos ou sutilmente curvados, sobre célula pericentral ou proximal; 2-4 células doliformes ou discóides com 3,0-9,0 $\mu \mathrm{m}$ comp. e 2,5-11,5 $\mu \mathrm{m}$ diâm. Carpogônios simétricos com 18,0-28,5 $\mu \mathrm{m}$ comp.; tricogíneos claviformes ou elípticos. Carposporófitos sésseis, 1-2 por verticilo, semi-esféricos, 80,0$270,0 \mu \mathrm{m}$ diâm. Carposporângios obovóides ou esféricos com

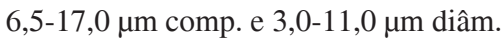

Distribuição no Sul do Brasil: pontos de amostragem 56, 96, 98, 99, 100, 102, 104 e 105. BRASIL. SANTA CATARINA: São Domingos, Parque Estadual das Araucárias, riacho sem denominação, na borda do parque, $26^{\circ} 29^{\prime} 25^{\prime}$ 'S e 52 34' 27' O, 15.VIII.2007, C.C.Z. Branco et al. s.n. (SJRP29771); idem. RIO GRANDE DO SUL: Cambará do Sul, Parque Nacional de Aparados da Serra, rio Camarinhas, $2^{\circ} 06^{\prime} 25^{\prime}$ ' S e 50 $00^{\circ}$ ' 30”' O, 01.VI.08, C.C.Z. Branco et al. s.n. (SJRP29788); idem, rio Camisas, $29^{\circ} 10^{\prime} 43^{\prime \prime} \mathrm{S}$ e $50^{\circ} 08^{\prime} 11^{\prime \prime}$ O, 31.V.2008, C.C.Z. Branco et al. s.n. (SJRP29785); idem, rio Preá, 2909' 48”' S e 5005' 49” O, 31.V.2008, C.C.Z. Branco et al. s.n. (SJRP29786); idem, rio Perdizes, 29 09' 27' S e 50 04' 09”' O, 31.V.2008, C.C.Z. Branco et al. s.n. (SJRP29787); idem, Parque Nacional da Serra Geral, rio do Segredo, 29॰04' 47” S, e 49 59' 17' O, 01.VI.08, C.C.Z. Branco et al. s.n. (SJRP29791); idem, riacho afluente do Segredo, 29 04' 36" S e 49 59' 05" O, 01.VI.08, C.C.Z. Branco et al. s.n. (SJRP29792); idem, riacho do mirante do Cânion Fortaleza, 2904' 00” S e 49 57' 44” O, 01.VI.08, C.C.Z. Branco et al. s.n. (SJRP29793).

Características ambientais $(n=8)$ : temperatura da água 6,2$17,5^{\circ} \mathrm{C}(\bar{x}=11,5 \pm 3,4)$; condutividade específica $11-32 \mu \mathrm{S} . \mathrm{cm}^{-1}$ $(\bar{x}=18 \pm 7) ; \mathrm{pH} 5,4-6,5(\bar{x}=5,9 \pm 0,3)$; oxigênio dissolvido 4,3-5,8 mg.L $\mathrm{L}^{-1}(\bar{x}=4,9 \pm 0,5)$; turbidez $1-32 \mathrm{NTU}(\bar{x}=9 \pm 11)$; velocidade da correnteza $15-79 \mathrm{~cm} \cdot \mathrm{s}^{-1}(\bar{x}=33 \pm 23)$; profundidade média $13-28 \mathrm{~cm}(\bar{x}=20 \pm 6)$.

Considerações taxonômicas: $B$. puiggarianum já foi registrado na região Sul do Brasil por Necchi Júnior (1990a) e as características diagnósticas das populações do material estudado encaixam-se nas descrições da espécie encontradas na literatura (Necchi Júnior 1990a, Kumano 2002).

Batrachospermum arcuatum Kylin (1912: 22, Figura 7 a-e) emend. Vis et al. (1995:52). (Figuras 10-13)

Plantas dióicas, com mucilagem moderada ou abundante e ramificações irregulares e abundantes; ápice reto, verticilos bem desenvolvidos, densos, esféricos ou discóides, contíguos ou separados, 130,0-535,0 $\mu \mathrm{m}$ diâm. Internós com 70,0-391,0 $\mu \mathrm{m}$ comp. Fascículos primários em geral retos com 8-15 células; 2-4 ramificações di ou tricotômicas; células proximais cilíndricas com
14,5-30,5 um comp. e 3,0-9,0 $\mu$ m diâm.; células distais obovóides ou claviformes com 8,0-14,5 $\mu \mathrm{m}$ comp. e 2,5-8,0 $\mu \mathrm{m}$ diâm. Fascículos secundários ausentes ou esparsos. Espermatângios esféricos ou ovais, terminais ou sub-terminais nos fascículos primários, 3,5-6,0 $\mu \mathrm{m}$ diâm. Ramos carpogoniais retos, sobre células basais ou proximais; $5-7(-8)$ células em geral doliformes com 3,0-8,5 $\mu \mathrm{m}$ comp. e 3,0-8,5 $\mu \mathrm{m}$ diâm. Carpogônios simétricos 7,0-25,5 um comp.; tricogíneos claviformes. Carposporófitos pedunculados, 1-2 por verticilo, esféricos, periféricos ou no interior do verticilo, 39,0-170,0 $\mu \mathrm{m}$ comp. Carposporângios

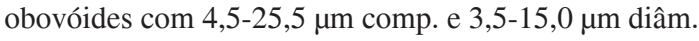

Distribuição no Sul do Brasil: pontos de amostragem 24, 59, 70, 72, 76 e 94. BRASIL. PARANÁ: Foz do Iguaçu, Parque Nacional do Iguaçu, riacho sem denominação, $25^{\circ} 09^{\prime} 38^{\prime \prime} \mathrm{S}$ e 534' 44”' O, 02.V.2008, C.C.Z. Branco et al. s.n. (SJRP29760); idem. SANTA CATARINA: Blumenau, Parque Nacional da Serra do Itajaí, rio da Prata, $27^{\circ} 02$ ' 17 ' S e $49^{\circ} 05^{\prime} 57^{\prime \prime} \mathrm{O}$, 28.V.2008, C.C.Z. Branco et al. s.n. (SJRP29745); idem. RIO GRANDE DO SUL: Parque Estadual Florestal do Turvo, rio Tigre, $27^{\circ} 12$ ' 25" S, 53 50' 02" O, 18.VIII.2007, C.C.Z. Branco et al. s.n. (SJRP29741); idem, rio Calisto, $27^{\circ} 13$ ' 49" S e 53 54' 92" O, 17.VIII.2007, C.C.Z. Branco et al. s.n. (SJRP29739); idem, rio Fábio, $27^{\circ} 16^{\prime} 32$ ”' S e 540' 56” O, 17.VIII.2007, C.C.Z. Branco et al. s.n. (SJRP29735); idem, Canela, Parque Estadual do Caracol, rio Tiririca, 29 18' 59” S, 50 51' 01” O, 02.VI.2008, C.C.Z. Branco et al. s.n. (SJRP29725).

Características ambientais $(n=6)$ : temperatura da água 10,3$18,1^{\circ} \mathrm{C}(\bar{x}=15,8 \pm 2,9)$; condutividade específica $28-46 \mu \mathrm{S} . c m^{-1}$ $(\bar{x}=33 \pm 7) ; \mathrm{pH} 6,2-7,2(\bar{x}=6,7 \pm 0,4)$; oxigênio dissolvido $3,8-6,2 \mathrm{mg} . \mathrm{L}^{-1}(\bar{x}=5,1 \pm 0,9)$; turbidez $1-33 \mathrm{NTU}(\bar{x}=10 \pm 13)$; velocidade da correnteza $21-102 \mathrm{~cm} \cdot \mathrm{s}^{-1}(\bar{x}=56 \pm 28)$; profundidade média $16-31 \mathrm{~cm}(\bar{x}=20 \pm 6)$.

Considerações taxonômicas: $B$. arcuatum já havia sido registrado anteriormente no país (Necchi Júnior (1990a), tratado como $B$. boryanum), porém, foi registrado pela primeira vez na região sul do Brasil. As características diagnósticas das populações do material estudado encaixam-se nas descrições da espécie encontradas na literatura (Necchi Júnior 1990a, Kumano 2002).

Batrachospermum keratophytum Bory, Ann. Mus. Hist. Nat. 12: 328, pl. 31, Figura 2. 1808.

Sinônimos: B. vagum (Roth) Agardh var. keratophytum (Bory) Sirodot, B. suevorum Kützing (Figuras 14-17)

Plantas monóicas, com pouca mucilagem e ramificações pseudodicotômicas abundantes; ápice reto, verticilos reduzidos, densos, obcônicos, em geral indistintos e contíguos, 106,0350,0 $\mu \mathrm{m}$ diâm. Internós com 91,0-392,0 $\mu \mathrm{m}$ comp. Fascículos primários retos com 4-11 células; 1-3 ramificações di ou tricotômicas; células proximais ovais ou obovóides, com 9,5-29,0 $\mu \mathrm{m}$ comp. e 6,0-21,5 $\mu \mathrm{m}$ diâm.; células distais ovais com 9,5-24,0 $\mu \mathrm{m}$ comp. e 5,0-17,5 $\mu \mathrm{m}$ diâm. Fascículos secundários numerosos ao longo do internó, podendo alcançar o comprimento dos fascículos primários; células proximais ovais ou obovóides com 8,0-26,0 $\mu \mathrm{m}$ comp. e 6,0-16,0 $\mu \mathrm{m}$ diâm.; células distais obovóides com 8,0-22,5 $\mu \mathrm{m}$ comp. e 5,5-13,0 $\mu \mathrm{m}$ diâm. Espermatângios esféricos, terminais ou sub-terminais, principalmente nos fascículos secundários, 3,5-8,5 $\mu \mathrm{m}$ diâm. Ramos carpogoniais retos, sobre a célula pericentral; 3-6 células discóides ou doliformes com 6,5-13,5 $\mu \mathrm{m}$ comp. e 6,0-10,0 $\mu \mathrm{m}$ diâm. Carpogônios simétricos com 33,5-71,5 $\mu \mathrm{m}$ comp.; tricogíneos claviformes, raramente sinuosos na base. 

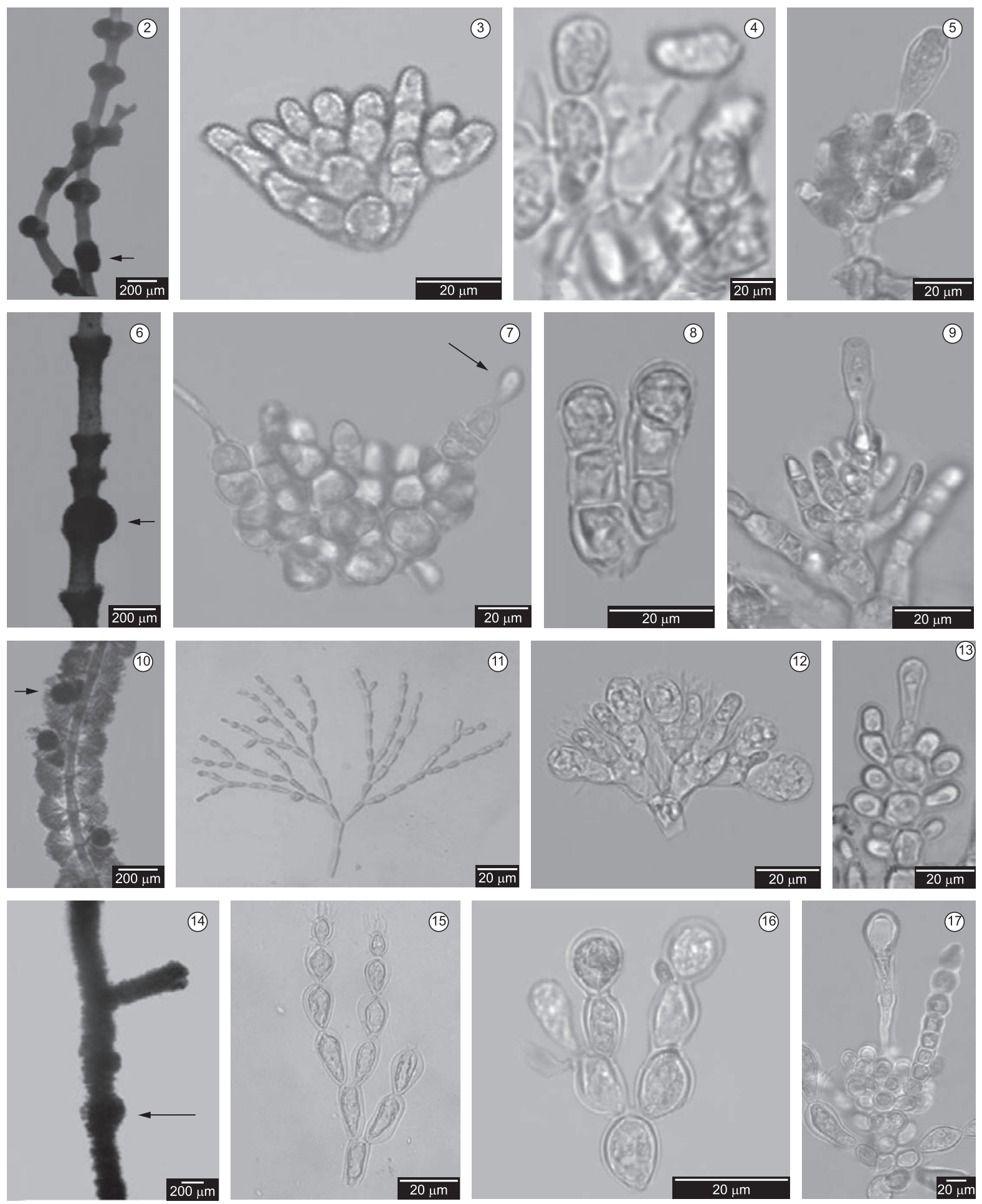

Figuras 2-17. Fotomicrografias das Rhodophyta de Unidades de Conservação da região Sul do Brasil. 2-5. Batrachospermum atrum. 2) Verticilo com carposporófito. 3) Fascículo primário audouinelóide. 4) Filamento gonimoblástico com carposporângio terminal. 5) Ramo carpogonial com carpogônio. 6-9. B. puiggarianum. 6) Verticilo com carposporófito. 7) Fascículo primário audouinelóide com carpogônio (seta). 8) Filamento gonimoblástico com carposporângios terminais. 9) Ramo carpogonial com carpogônio. 10-13. B. arcuatum. 10) Verticilo com carposporófito pedunculado. 11) Fascículo primário. 12) Filamentos gonimoblástico com carposporângios terminais. 13) Ramo carpogonial com carpogônio. 14-17. B. keratophytum. 14) Verticilo com carposporófito. 15) Fascículo primário. 16) Filamento gonimoblástico

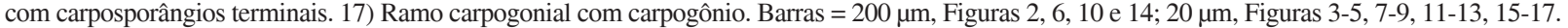

Figures 2-17. Photomicrography of Rhodophyta from Conservation Units of Southern Brazil. 2-5. Batrachospermum atrum. 2) Whorls showing carposporophytes. 3) Primary fascicle audouinelloid. 4) Gonimoblastic filament with terminal carposporangia. 5) Carpogonium-bearing branch with carpogonium. 6-9. B. puiggarianum. 6) Whorls showing carposporophyte. 7) Primary fascicle audouinelloid with carpogonium (arrow). 8) Gonimoblastic filament with terminal carposporangia. 9. Carpogonium-bearing branch with carpogonium. 10-13. B. arcuatum. 10. Whorls showing pedunculate carposporophyte. 11. Primary fascicle. 12. Gonimoblastic filament with terminal carposporangia. 13. Carpogonium-bearing branch with carpogonium. 14-17. B. keratophytum. 14. Whorls showing carposporophyte. 15. Primary fascicle. 16. Gonimoblastic filament with terminal carposporangia. 17. Carpogonium-bearing branch with carpogonium. Bars $=200 \mu \mathrm{m}$, Figures 2, 6, 10 and 14; $20 \mu \mathrm{m}$, Figures 3-5, 7-9, 11-13, 15-17. 
Carposporófitos sésseis, 1 por verticilo, frouxos, semi-esféricos, 197,5-465,0 $\mu \mathrm{m}$ diâm. Carposporângios esféricos com 10,015,0 $\mu \mathrm{m}$ de comp. e 7,0-10,0 $\mu \mathrm{m}$ de diâm.

Distribuição no Sul do Brasil: pontos de amostragem 14, 99 e 100. BRASIL. PARANÁ: Ponta Grossa, Parque Estadual de Vila Velha, riacho da Taipa, 25 13' 17" S e 50 00' 44" O, 03.V.2008, C.C.Z. Branco et al. s.n. (SJRP29774); idem. RIO GRANDE DO SUL: Cambará do Sul, Parque Nacional da Serra Geral, riacho afluente do Segredo, 2904' 36”'S e 49 59' 05” O, 01.VI.2008, C.C.Z. Branco et al. s.n. (SJRP29792); idem, riacho do mirante do Cânion Fortaleza, 29 04' 00”'S e 49 57' 44”' O, 01.VI.2008, C.C.Z. Branco et al. s.n. (SJRP29793).

Características ambientais $(n=3)$ : temperatura da água 13,1$15,9^{\circ} \mathrm{C}(\bar{x}=14,3 \pm 1,4)$; condutividade específica $11-21 \mu \mathrm{S} . c m^{-1}$ $(\bar{x}=14 \pm 6)$; pH 5,2-5,6 ( $\bar{x}=5,4 \pm 0,2)$; oxigênio dissolvido 4-4,7 mg.L $\mathrm{L}^{-1}(\bar{x}=4,4 \pm 0,3)$; turbidez $2-3 \mathrm{NTU}(\bar{x}=2 \pm 1)$; velocidade da correnteza 16-92 cm.s ${ }^{-1}(\bar{x}=44 \pm 42)$; profundidade média $13-33 \mathrm{~cm}(\bar{x}=22 \pm 10)$.

Considerações taxonômicas: $B$. keratophytum já havia sido registrado na região Sul do Brasil por Necchi Júnior (1990a). No presente estudo, os espécimes registrados no ponto de amostragem 14 apresentaram diferenças importantes para algumas características morfométricas em relação aos espécimes das demais populações do Sul do Brasil (pontos de amostragem 99 e 100) e em relação aos espécimes descritos na literatura. Macroscopicamente observou-se que as plantas dessa população eram menores, com consistência menos cartilaginosa e coloração mais clara. A análise microscópica revelou diferenças na forma e comprimento do carpogônio. Na literatura (Necchi Júnior 1990a, Kumano 2002), o comprimento desta estrutura tem uma variação entre $36,0-47,0 \mu \mathrm{m}$, valores muito próximos aos observados nas populações dos pontos de amostragem 99 e 100 (entre 33,5-46,0 $\mu \mathrm{m}$ ). Entretanto, o carpogônio da população do ponto 14 variou entre 48,0-71,5 $\mu \mathrm{m}$. Em adição, esses apresentaram tricogíneo sinuoso na base, o que não é documentado na literatura e nem foi encontrado nas populações dos pontos de amostragem 99 e 100, cujo formato era uniformemente claviforme. Contudo, mesmo considerando estas diferenças morfométricas observadas nas plantas coletadas no ponto 14 , as características estruturais qualitativas das plantas desta população concordam com aquelas descritas como diacríticas para B. keratophytum (p. ex., verticilos reduzidos e retos com fascículos primários não-auduinelóides, espermatângios principalmente nos fascículos secundários e carposporângios esféricos ou sub-esféricos). Assim, entendemos que tais diferenças devam ser tratadas com sendo variações populacionais.

Batrachospermum helminthosum Bory, Ann. Mus. Hist. nat. 12: 316, pl. 29, Figura 2. 1808.

Sinônimos: B. graibussoniense Sirodot, B. bruziense Sirodot, B. testale Sirodot, B. sirodotii Skuja ex Flint, B. vogesiacum Schultz ex Skuja. (Figuras 18-21)

Plantas dióicas, com mucilagem moderada ou abundante e ramificações irregulares e abundantes; ápice reto, verticilos bem desenvolvidos, densos ou frouxos, esféricos ou obcônicos, contíguos ou separados, 200,0-960,0 $\mu \mathrm{m}$ diâm. Internós com 200,0-960,0 $\mu \mathrm{m}$ comp. Fascículos primários retos com 6-12 células; 3-4(-5) ramificações di ou tricotômicas; células proximais cilíndricas com 20,0-60,0 $\mu$ m comp. e 4,5-20,5 $\mu$ m diâm.; células distais claviformes, ovais ou obovóides com 5,0-18,0 $\mu$ m comp. e 3,0-9,0 $\mu \mathrm{m}$ diâm. Fascículos secundários usualmente abundantes, às vezes esparsos, distribuídos ao longo da extensão do internó ou apenas próximos dos fascículos primários, geralmente alcançam o comprimento do fascículo primário; células proximais cilíndricas ou claviformes com 20,0-33,0 $\mu \mathrm{m}$ de comp. e 5,0-12,5 $\mu \mathrm{m}$ diâm.; células distais claviformes com 10,0-27,0 $\mu \mathrm{m}$ comp. e 4,5-9,5 $\mu \mathrm{m}$ diâm. Espermatângios esféricos ou ovais, terminais ou sub-terminais nos fascículos primários ou secundários, 4,010,0 $\mu \mathrm{m}$ diâm. Ramos carpogoniais retos, sobre célula pericentral ou proximal; 2-5 células discóides, doliformes ou cilíndricas com 8,5-14,5 $\mu \mathrm{m}$ de comp. e 6,0-13,5 $\mu \mathrm{m}$ diâm. Carpogônios simétricos, 60,0-93,0 $\mu \mathrm{m}$ comp.; tricogíneos cilíndricos ou claviformes, pedicelados. Carposporófitos sésseis, 1-2 por verticilo, esféricos ou semi-esféricos, 263,0-500,0 $\mu \mathrm{m}$ diâm. Carposporângios obovóides ou elípticos com 12,0-34,5 $\mu \mathrm{m}$ de comp. e 10,0-19,0 $\mu \mathrm{m}$ de diâm.

Distribuição no Sul do Brasil: pontos de amostragem 9, 11, 51, 53, 54, 55, 56, 82, 85, 96, 102 e 105. BRASIL. PARANÁ: Teixeira Soares, Floresta Nacional de Irati, riacho localizado a 400 metros da estrada principal, linha da Copel 1, 25 23' 07' S e 50 35' 27" O, 21.VII.2005, 04.II.2006, C.C.Z. Branco et al. s.n. (SJRP28239); idem, riacho no talhão 80, nas imediações do viveiro, $25^{\circ} 24^{\prime} 16^{\prime \prime} \mathrm{S}$ e $50^{\circ} 35^{\prime} 28^{\prime \prime} \mathrm{O}, 19$.VII.2005, 02.II.2006, C.C.Z. Branco et al. s.n. (SJRP28241); idem. SANTA CATARINA: São Domingos, Parque Estadual das Araucárias, riacho sem denominação, $26^{\circ} 27^{\prime} 21^{\prime \prime} \mathrm{S}$ e $52^{\circ} 33^{\prime} 41^{\prime \prime} \mathrm{O}$, 14.VIII.2007, C.C.Z. Branco et al. s.n. (SJRP29766); idem, riacho afluente do rio Jacutinga, $26^{\circ} 28^{\prime} 15^{\prime \prime} \mathrm{S}$ e $52^{\circ} 34^{\prime} 20^{\prime \prime} \mathrm{O}$, 14.VIII.2007, C.C.Z. Branco et al. s.n. (SJRP29763); idem, rio Jacutinga, 26 $28^{\circ}$ '08" S e 52 34' 00" O, 14.VIII.2007, C.C.Z. Branco et al. s.n. (SJRP29764); riacho sem denominação, fora dos limites do parque. $26^{\circ} 28^{\prime} 48^{\prime \prime} \mathrm{S}$ e $52^{\circ} 34^{\prime} 32^{\prime \prime}$ O, C.C.Z. Branco et al. s.n. (SJRP29770); idem, riacho sem denominação, fora dos limites do parque. $26^{\circ} 29^{\prime} 25^{\prime \prime} \mathrm{S}$ e $52^{\circ} 34^{\prime} 27^{\prime \prime} \mathrm{O}$, C.C.Z. Branco et al. s.n. (SJRP29771); idem, Concórdia, Parque Estadual Fritz Plaumann, riacho sem denominação, $27^{\circ} 17$ ' 28” S, 52 06' 37' O, 19.VIII.2007, C.C.Z. Branco et al. s.n. (SJRP29716); idem, rio Bugre, $27^{\circ} 18^{\prime} 22^{\prime}$ ' S e 52 05' 51" O, 19.viii.2007, C.C.Z. Branco et al. s.n. (SJRP29719); idem. RIO GRANDE DO SUL: Cambará do Sul, Parque Nacional de Aparados da Serra, rio Camarinhas, 29 06' 25" S e $50^{\circ} 07$ ' 30” O, 01.VI.2008, C.C.Z. Branco et al. s.n. (SJRP29788); idem, rio Camisas, $29^{\circ} 10^{\prime} 43^{\prime \prime} \mathrm{S}$ e $50^{\circ} 08^{\prime} 11^{\prime \prime} \mathrm{O}, 31 . \mathrm{V} .2008$, C.C.Z. Branco et al. s.n. (SJRP29785); idem, rio Perdizes, 2909' 27' S e 5004'09” W e 31.V.2008, C.C.Z. Branco et al. s.n. (SJRP29787).

Características ambientais $(\mathrm{n}=12)$ : temperatura da água 6,2$19,4{ }^{\circ} \mathrm{C}(\bar{x}=13,9 \pm 4,0)$; condutividade específica $17-59 \mu \mathrm{S} . \mathrm{cm}^{-1}$ $(\bar{x}=32 \pm 12,3)$; pH 5,6-6,8 ( $\bar{x}=6,3 \pm 0,4)$; oxigênio dissolvido 4,3-6,8 mg.L. $\mathrm{L}^{-1}(\bar{x}=5,6 \pm 0,6)$; turbidez 1-43 NTU $(\bar{x}=12 \pm 13)$; velocidade da correnteza $15-56,1 \mathrm{~cm} \cdot \mathrm{s}^{-1}(\bar{x}=38,8 \pm 13,6)$; profundidade média $6-36 \mathrm{~cm}(\bar{x}=17,6 \pm 8,8)$.

Considerações taxonômicas: Neste trabalho adotamos a proposição de Sheath et al. (1994a), que considera B. sirodotii e B. vogesiacum sinônimos de B. helminthosum. Os caracteres empregados anteriormente por Necchi Júnior (1990a) para separar as três espécies (número de células dos fascículos primários e abundância dos fascículos secundários) não se mostraram de valor diagnóstico para distinguir os espécimes da região Sul do Brasil, isto é, encontramos populações com características intermediárias. Trabalhos recentes utilizando sequências de DNA (Hanyuda et al. 2004, Necchi Júnior, dados não publicados) indicaram a existência de linhagens com evidente separação geográfica de B. helminthosum: Brasil, EUA e Japão. Estes trabalhos confirmaram ainda que para o Brasil a variação encontrada não permite a separação em mais de uma espécie. 


\section{'Chantransia' macrospora (Figura 22)}

Filamentos retos unisseriados formando tufos. Ramificação com ângulos menores do que $25^{\circ}$. Coloração, em geral, verde acinzentada. Células do eixo principal cilíndricas com 42,0128,5 $\mu$ m comp. e 15,5-49,0 $\mu \mathrm{m}$ diâm. Células da ramificação cilíndricas ou doliformes com 39,0-91,5 $\mu \mathrm{m}$ comp. e 15,0-25,0 $\mu \mathrm{m}$ diâm. Monosporângios esféricos ou obovóides com 22,0-48,5 $\mu \mathrm{m}$ diâm.

Distribuição no Sul do Brasil: pontos de amostragem 31, 43, 57, 62, 65 e 66. BRASIL. PARANÁ: Foz do Iguaçu, Parque Nacional do Iguaçu, junção do rio Apepú com Apepuzinho, 25 32' 03” S e 54 18' 08” O, 30.IV.2008, C.C.Z. Branco et al. s.n. (SJRP29754); idem, Matinhos, Parque Nacional Saint-Hilaire/Lange, cachoeira do Tigre, rio Cachoeira, 25 44' 27" S e 48 36' 66" O, 2.VII.2005, C.C.Z. Branco et al. s.n. (UPCB53116); idem. SANTA CATARINA: Indaial, Parque Nacional da Serra do Itajaí, rio Encano, $27^{\circ} 01^{\prime} 22^{\prime}$ 'S e 49 09' 39” O, 29.V.2008, C.C.Z. Branco et al. s.n. (SJRP29751); idem, Blumenau, Parque Nacional da Serra do Itajaí, ribeirão Frio, $27^{\circ} 02^{\prime} \mathrm{S}$ e $49^{\circ} 05^{\prime} \mathrm{W}$ 28.V.2008, C.C.Z. Branco et al. s.n. (SJRP29746); idem, rio Garcia Pequeno, $27^{\circ} 03$ ' 27' S e 49 04' 42”' O, 29.V.2008, C.C.Z. Branco et al. s.n. (SJRP29749); idem, rio Abelha, $27^{\circ} 02^{\prime} \mathrm{S}$ e 4905' O, 29.V.2008, C.C.Z. Branco et al. s.n. (SJRP29747).

Características ambientais $(n=6)$ : temperatura da água 17,6$20,0{ }^{\circ} \mathrm{C}(\bar{x}=18,2 \pm 0,9)$; condutividade específica $15-30 \mu \mathrm{S} . \mathrm{cm}^{-1}$ $(\bar{x}=22 \pm 5) ; \mathrm{pH}$ 6,1-6,9 $(\bar{x}=6,4 \pm 0,3)$; oxigênio dissolvido $3,4-6,5 \mathrm{mg} \cdot \mathrm{L}^{-1}(\bar{x}=4,2 \pm 1,2)$; turbidez $0-38 \mathrm{NTU}(\bar{x}=11 \pm$ 16); velocidade da correnteza $60-233 \mathrm{~cm} \cdot \mathrm{s}^{-1}(\bar{x}=102 \pm 66)$; profundidade média $6-28 \mathrm{~cm}(\bar{x}=17 \pm 8)$.

Considerações taxonômicas: Seguimos a recomendação de Pueschel et al. (2000), de que os espécimes do estágio 'Chantransia' devem ser informalmente separados em duas morfologias distintas: 'Chantransia' pygmaea e 'Chantransia' macrospora.

'Chantransia' pygmaea (Figura 23)

Filamentos eretos unisseriados formando tufos. Ramificação com ângulos menores do que $25^{\circ}$. Coloração, em geral, verde acinzentada. Células do eixo principal cilíndricas com 12,549,5 $\mu \mathrm{m}$ comp. e 6,0-20,5 $\mu \mathrm{m}$ diâm. Células da ramificação cilíndricas ou doliformes com 9,0-53,0 $\mu \mathrm{m}$ comp. e 5,0-19,0 $\mu \mathrm{m}$ diâm. Monosporângios esféricos ou obovóides com 5,0-21,0 $\mu \mathrm{m}$ diâm.

Distribuição no Sul do Brasil: pontos de amostragem 22, 23, $24,25,26,27,28,29,30,36,45,47,52,53,55,56,61,67$, 72, 81, 88, 90, 91, 94, 96, 97, 102 e 104. BRASIL. PARANÁ: Foz do Iguaçu, Parque Nacional do Iguaçu, riacho sem

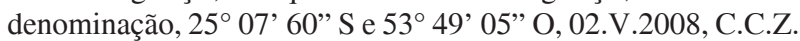
Branco et al. s.n. (SJRP29762); idem, riacho sem denominação, 2509' 30" S, 53 50' 09” W e 02.V.2008, C.C.Z. Branco et al. s.n. (SJRP29761); idem, riacho sem denominação, 2509' 38' S e 534' 44”' O, 02.V.2008, C.C.Z. Branco et al. s.n. (SJRP29760); idem, rio São João, $25^{\circ} 37^{\prime} 12^{\prime \prime}$ S e $54^{\circ} 28^{\prime} 34$ " O, 01.V.2008, C.C.Z. Branco et al. s.n. (SJRP29759); idem, riacho sem denominação, 25 37' 20" S e 54 26' 52” O, 01.V.2008, C.C.Z. Branco et al. s.n. (SJRP29758); idem, riacho sem denominação, 2536' 46" S e 54 25' 49" O, 01.V.2008, C.C.Z. Branco et al. s.n. (SJRP29757); idem, riacho sem denominação, 25³6' 13" S e 54 24' 50" O, 01.V.2008, C.C.Z. Branco et al. s.n. (SJRP29756); idem, riacho sem denominação, $25^{\circ} 35^{\prime} 41^{\prime \prime} \mathrm{S}$ e $54^{\circ} 23^{\prime} 30^{\prime \prime} \mathrm{O}$, 01.V.2008, C.C.Z. Branco et al. s.n. (SJRP29755); idem, rio Apepuzinho, 25 32' 01' S e 54 19' 36" O, 30.IV.2008, C.C.Z. Branco et al. s.n. (SJRP29753); idem, Guaratuba, Parque Nacional
Saint-Hilaire/Lange, afluente do rio do Henrique, 25 40' 54' S, $48^{\circ} 42$ ' 15" W e 26.XI.2005, C.C.Z. Branco et al. s.n. (UPCB53132); idem, Matinhos, Parque Nacional Saint-Hilaire/ Lange, rio Indaial, $25^{\circ} 47^{\prime} 79^{\prime \prime} \mathrm{S}$ e $48^{\circ} 34^{\prime} 01$ ' O, 3.VII.2005, C.C.Z. Branco et al. s.n. (UPCB53130); idem. SANTA CATARINA: São Domingos, Parque Estadual das Araucárias, riacho afluente do Rio Jacutinga, $26^{\circ} 27^{\prime} 21^{\prime \prime} \mathrm{S}$ e $52^{\circ} 34^{\prime} 42^{\prime \prime} \mathrm{O}$, 15.VIII.2007, C.C.Z. Branco et al. s.n. (SJRP29772); idem, riacho da divisa, $26^{\circ} 28^{\prime} 20^{\prime \prime} \mathrm{S}$ e $52^{\circ} 35^{\prime} 26^{\prime \prime}$ O, 15.VIII.2007, C.C.Z. Branco et al. s.n. (SJRP29769); idem, riacho afluente do rio Jacutinga, $26^{\circ} 28^{\prime} 15^{\prime}$ 'S e 52 $34^{\prime}$ '20” O, 14.VIII.2007, C.C.Z. Branco et al. s.n. (SJRP29763); idem, riacho sem denominação, na borda do parque, $26^{\circ} 28^{\prime} 48^{\prime}$ ' S e 52 $32^{\circ}$ '32" O, 15.VIII.2007, C.C.Z. Branco et al. s.n. (SJRP29770); idem, riacho sem denominação, na borda do parque, 26 29' 25' S e 52 34' 27' O, 15.VIII.2007, C.C.Z. Branco et al. s.n. (SJRP29771); idem, Blumenau, Parque Nacional da Serra do Itajaí, rio Garcia, $27^{\circ}$ 02' 55" S e 49 05' 32”' O, 28.V.2008, C.C.Z. Branco et al. s.n. (SJRP29743); idem, Concórdia, Parque Estadual Fritz Plaumann, rio Cruzeiro, $27^{\circ} 17^{\prime} 20^{\prime}$ 'S e 52 06' 49”' O, 19.VIII.2007, C.C.Z. Branco et al. s.n. (SJRP29715); idem. RIO GRANDE DO SUL: Parque Estadual Florestal do Turvo, rio Portinho, $27^{\circ} 08^{\prime}$ 06” S e 53 52' 53" O, 16.VIII.2007, C.C.Z. Branco et al. s.n. (SJRP29734); idem, rio Calisto, 27 13' 49”' S e 53 54' 92" O, 17.VIII.2007, C.C.Z. Branco et al. s.n. (SJRP29739); idem, Canela, Parque Estadual do Caracol, riacho da guarita do Parque da Ferradura, 29 16' 36" S e 50 50' 55" O, 03.VI.2008, C.C.Z. Branco et al. s.n. (SJRP29730); idem, afluente do rio Graxaim, 29॰16' 43” S e 50 50'34” O, 03.VI.2008, C.C.Z. Branco et al. s.n. (SJRP29731); idem, riacho da estrada para o Parque da Ferradura, $29^{\circ} 16^{\prime} 52^{\prime \prime} \mathrm{S}$ e $50^{\circ} 50^{\prime}$ 52" O, 02.VI.2008, C.C.Z. Branco et al. s.n. (SJRP29727); idem, rio Tiririca, 29 18' 59" S e 50 51' 01”' O, 02.VI.2008, C.C.Z. Branco et al. s.n. (SJRP29725); idem, Cambará do Sul, Parque Nacional de Aparados da Serra, rio Camarinhas, $29^{\circ} 06^{\prime} 25^{\prime \prime} \mathrm{S}$ e 50 $0^{\circ} 07^{\prime} 30^{\prime \prime}$ O, 01.VI.08, C.C.Z. Branco et al. s.n. (SJRP29788); idem, rio Camisas, 29 10' 43" S e 5008' 11" O, 31.V.2008, C.C.Z. Branco et al. s.n. (SJRP29785); idem, rio Preá, 290 09' 48”' S e 50 05' 49” O, 31.V.2008, C.C.Z. Branco et al. s.n. (SJRP29786); idem, Parque Nacional da Serra Geral, riacho próximo a entrada principal do parque, $29^{\circ} 04^{\prime} 58^{\prime \prime}$ S e 4959’ 41” O, 01.VI.08, C.C.Z. Branco et al. s.n. (SJRP29790).

Características ambientais $(\mathrm{n}=28)$ : temperatura da água 6,2$20,8{ }^{\circ} \mathrm{C}(\bar{x}=15,0 \pm 3,6)$; condutividade específica $1-59 \mu \mathrm{S} . \mathrm{cm}^{-1}$ $(\bar{x}=26 \pm 15) ; \mathrm{pH} 5,3-7,1(\bar{x}=6,2 \pm 0,5)$; oxigênio dissolvido $3,2-6,4$ mg.L $\mathrm{L}^{-1}(\bar{x}=4,9 \pm 0,8)$; turbidez 1-86 NTU ( $\left.\bar{x}=15 \pm 18\right)$; velocidade da correnteza $14-102 \mathrm{~cm} \cdot \mathrm{s}^{-1}(\bar{x}=43 \pm 26)$; profundidade média $3-34 \mathrm{~cm}(\bar{x}=17 \pm 8)$.

Kumanoa abilii (Reis) Necchi Júnior \& Vis, Phycologia 49(1): $97-$ 103. 2010.

\section{Basiônimo: Batrachospermum abilii M.P. dos Reis}

Sinônimos: B. virgato-decaisneanum Sirodot, B. mikrogyne Flint \& Skuja in Flint. (Figuras 24-27)

Plantas monóicas, mucilagem moderada e ramificações irregulares e abundantes; ápice reto, verticilos bem desenvolvidos, densos ou frouxos, obcônicos ou doliformes, em geral contíguos, 180,0-320,0 $\mu \mathrm{m}$ diâm. Internós com 80,0-240,0 $\mu \mathrm{m}$ comp. Fascículos primários com 5-10 células; 2-4 ramificações di ou tricotômicas; células proximais cilíndricas ou elípticas com 19,033,0 $\mu \mathrm{m}$ comp. e 3,5-8,0 $\mu \mathrm{m}$ diâm.; células distais elípticas ou 
obovóides com 7,5-20,0 $\mu$ m comp. e 5,0-9,5 $\mu$ m diâm. Fascículos secundários numerosos, ao longo da extensão do internó, geralmente alcançam o comprimento dos fascículos primários. Espermatângios em geral esféricos, terminais ou sub-terminais, nos fascículos primários ou secundários, 3,5-7,0 $\mu \mathrm{m}$ diâm. Ramos carpogoniais curvos, diferenciados dos fascículos, sobre células pericentrais; 1-7 células discóides ou doliformes com 3,5-9,5 $\mu \mathrm{m}$ comp. e 4,0-7,5 $\mu \mathrm{m}$ diâm. Carpogônios assimétricos, 23,0-43,0 $\mu \mathrm{m}$ comp.; tricogíneos cilíndricos, claviformes ou lanceolados, em geral pedicelados. Carposporófitos sésseis, 1 por verticilo, densos, semi-esféricos, 120,0-325,0 $\mu \mathrm{m}$ diâm. Carposporângios obovóides com 12,5-18,5 $\mu \mathrm{m}$ comp. e 7,0$12,0 \mu \mathrm{m}$ diâm.

Distribuição no Sul do Brasil: ponto de amostragem 17. BRASIL. PARANÁ: Ponta Grossa, Parque Estadual de Vila Velha, riacho dos Bombeiros, 25 13 ' 57' S e 49 $58^{\prime} 15^{\prime \prime} \mathrm{O}$, 04.V.2008, C.C.Z. Branco et al. s.n. (SJRP29779).

Características ambientais $(n=1)$ : temperatura da água $16,5^{\circ} \mathrm{C}$; condutividade específica $7 \mu \mathrm{S} . \mathrm{cm}^{-1} ; \mathrm{pH} 4,9$; oxigênio dissolvido 4,5 mg.L $\mathrm{L}^{-1}$; turbidez $7 \mathrm{NTU}$; velocidade da correnteza $76 \mathrm{~cm} . \mathrm{s}^{-1}$; profundidade média $18 \mathrm{~cm}$.

Considerações taxonômicas: $K$. abilii já foi registrada na região Sul do Brasil por Necchi Júnior (1990a), porém era tratado ainda como B. virgato-decaisneanum. As características diagnósticas das populações do material estudado encaixam-se nas descrições da espécie encontradas na literatura (Necchi Júnior 1990a, Kumano 2002).

Kumanoa ambigua (Montagne) Entwisle, Vis, Chiasson, Necchi Júnior \& Sherwood, J. Phycol. 45(3): 704-715, 2 Figuras, 1 Table. 2009.

\section{Basiônimo: Batrachospermum ambiguum Montagne}

Sinônimos: B. ambiguum Montagne, B. bicudoi Necchi, B. exsertum Necchi, B. basilare Flint \& Skuja in Flint (Figuras 28-31)

Plantas monóicas, mucilagem moderada e ramificações irregulares e abundantes; ápice reto, verticilos bem desenvolvidos, densos ou frouxos, obcônicos ou doliformes, em geral contíguos,

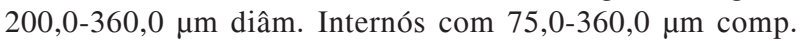
Fascículos primários com 5-10 células; 2-4 ramificações dicotômicas; células proximais em geral cilíndricas com 10,025,0 $\mu \mathrm{m}$ comp. e 4,0-8,0 $\mu \mathrm{m}$ diâm.; células distais claviformes

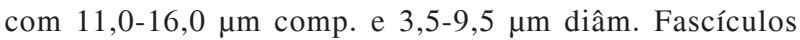
secundários numerosos, ao longo da extensão do internó, geralmente alcançam o comprimento dos fascículos primários. Espermatângios esféricos, terminais nos fascículos primários ou secundários, 4,5-8,0 $\mu \mathrm{m}$ diâm. Ramos carpogoniais torcidos helicoidalmente, diferenciados dos fascículos, sobre células pericentrais; 4-8 células discóides ou doliformes com 6,0-

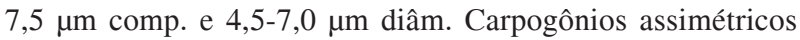
com 17,5-29,0 $\mu$ m comp.; tricogíneos cilíndricos ou claviformes, pedicelados. Carposporófitos sésseis, 1 por verticilo, densos, semi-esféricos, 95,0-210,0 um diâm. Carposporângios obovóides com 10,0-17,5 $\mu$ m comp. e 6,5-10,5 $\mu$ m diâm.

Distribuição no Sul do Brasil: pontos de amostragem 31, 34, 94. BRASIL. PARANÁ: Foz do Iguaçu, Parque Nacional do Iguaçu, junção do rio Apepú com Apepuzinho, 2532' 03” S e 54 18' 08”' O, 30.IV.2008, C.C.Z. Branco et al. s.n. (SJRP29754); idem, Paranaguá, Parque Nacional Saint-Hilaire/Lange, rio das Pombas, $25^{\circ} 39^{\prime} 18^{\prime \prime} \mathrm{S}$ e $48^{\circ} 35^{\prime} 42^{\prime \prime}$ O, 3.VII.2005, C.C.Z. Branco et al. s.n. (UPCB53124); idem. RIO GRANDE DO SUL: Canela, Parque Estadual do Caracol, rio Tiririca, 29 $18^{\prime} 59^{\prime \prime} \mathrm{S}$ e 50 51' 01”' O, 02.VI.2008, C.C.Z. Branco et al. s.n. (SJRP29725).
Características ambientais $(n=3)$ : temperatura da água 10,3$19,8^{\circ} \mathrm{C}(\bar{x}=15,9 \pm 5,0)$; condutividade específica $20-37 \mu \mathrm{S} . c m^{-1}$ $(\bar{x}=28 \pm 8) ; \mathrm{pH} 6,2-6,6(\bar{x}=6,3 \pm 0,2)$; oxigênio dissolvido 4,5-5 mg.L $\mathrm{L}^{-1}(\bar{x}=4,7 \pm 0,3)$; turbidez 2-38 NTU ( $\left.\bar{x}=15 \pm 19\right)$; velocidade da correnteza $62-92 \mathrm{~cm}^{-1}(\bar{x}=73 \pm 16)$; profundidade média $16-24 \mathrm{~cm}(\bar{x}=19 \pm 4)$.

Considerações taxonômicas: $K$. ambigua já foi registrada para a região Sul do Brasil por Necchi Júnior (1990a - tratada como B. bicudoi) e por Peres et al. (2008). Em descrições anteriores (Kumano 2002, Necchi Júnior 1990a), o comprimento do carpogônio variou entre 22,0-65,0 $\mu \mathrm{m}$ e o diâmetro do carposporófito entre 200,0-450,0 $\mu \mathrm{m}$ (Necchi Júnior 1990a) e entre 120,0-450,0 $\mu \mathrm{m}$ (Kumano 2002). Percebe-se, então, que os espécimes do presente estudo apresentaram, em regra, variações morfométricas próximas ou abaixo do limite mínimo daquelas registradas nos estudos comparados acima, realizados no Brasil e outras partes do mundo.

\section{CLASSE FLORIDEOPHYCEAE}

\section{ORDEM HILDENBRANDIALES}

Hildenbrandia angolensis Welwitsch ex W.West \& G.S.West, J. Bot. 35: 3, 1897. (Figuras 32-33)

Plantas crostosas, fortemente aderidas ao substrato, formando manchas circulares ou irregulares, vermelho-escuras ou pretas, formadas por filamentos prostrados e eretos. Filamentos prostrados ramificados e de crescimento indeterminado. Filamentos eretos, pouco ramificados, densamente agregados. Células mais largas do que longas, em geral doliformes com 2,9-16,2 $\mu$ m comp. e 4,8-23,2 $\mu \mathrm{m}$ diâm. Estruturas reprodutivas (gemas) não observadas.

Distribuição no Sul do Brasil: pontos de amostragem 16, 27, 54, 56, 62, 63, 64, 65, 66, 69, 72 e 90. BRASIL: PARANÁ: Ponta Grossa, Parque Estadual de Vila Velha, riacho atrás dos arenitos da Fortaleza, 25 13'36" S e 5000' 00”' O, 05.V.2008, C.C.Z. Branco et al. s.n. (SJRP29781); idem, Foz do Iguaçu, Parque Nacional do Iguaçu, riacho sem denominação, $25^{\circ} 36^{\prime} 46^{\prime \prime} \mathrm{S}$ e 542 25' 49”' O, 01.V.2008 C.C.Z. Branco et al. s.n. (SJRP29757); idem. SANTA CATARINA: São Domingos, Parque Estadual das Araucárias, rio Jacutinga, $26^{\circ} 28^{\prime} 08^{\prime \prime} \mathrm{S}$ e 52 34'00" O, 14.VIII.2007, C.C.Z. Branco et al. s.n. (SJRP29764); idem, riacho sem denominação, na borda do parque, $26^{\circ} 29^{\prime} 25^{\prime \prime} \mathrm{S}$ e 52 34' 27" O, 15.VIII.2007, C.C.Z. Branco et al. s.n. (SJRP29771); idem, Blumenau, Parque Nacional da Serra do Itajaí, rio Garcia Pequeno, $27^{\circ} 03^{\prime} 27^{\prime \prime} \mathrm{S}$ e $49^{\circ} 04^{\prime} 42^{\prime \prime} \mathrm{O}$, 29.V.2008, C.C.Z. Branco et al. s.n. (SJRP29749); idem, riacho Garrafa, $27^{\circ} 03$ ' 52" S e 49 05' 35" O, 29.V.2008, C.C.Z. Branco et al. s.n. (SJRP29750); idem, riacho Chuveiro, $27^{\circ} 02^{\prime} \mathrm{S}$ e $49^{\circ}$ 05' O, 29.V.2008, C.C.Z. Branco et al. s.n. (SJRP29748); idem, rio Abelha, $27^{\circ} 02^{\prime} \mathrm{S}$ e $49^{\circ} 05^{\prime}$ O, 29.V.2008, C.C.Z. Branco et al. s.n. (SJRP29747); idem, ribeirão Frio, $27^{\circ} 02^{\prime}$ S e 49 05' O, 28.V.2008, C.C.Z. Branco et al. s.n. (SJRP29746); idem. RIO GRANDE DO SUL: Parque Estadual Florestal do Turvo, riacho sem denominação, $27^{\circ} 11^{\prime} 57^{\prime}$ 'S e 53 49' 31" O, 18.VIII.2007, C.C.Z. Branco et al. s.n. (SJRP29742); idem, rio Calisto, $27^{\circ} 13$ ' 49" S e 53 54' 92" O, 17.VIII.2007, C.C.Z. Branco et al. s.n. (SJRP29739); idem, Canela, Parque Estadual do Caracol, afluente do rio Graxaim, 29 $16^{\prime} 43^{\prime \prime} \mathrm{S}$ e 50 50' $34^{\prime \prime} \mathrm{O}$, 03.VI.2008, C.C.Z. Branco et al. s.n. (SJRP29731).

Características ambientais $(\mathrm{n}=11)$ : temperatura da água 11,6$18,3{ }^{\circ} \mathrm{C}(\bar{x}=16,6 \pm 1,9)$; condutividade específica $1-46 \mu \mathrm{S} . \mathrm{cm}^{-1}$ $(\bar{x}=23 \pm 13) ; \mathrm{pH} 4,8-7,1(\bar{x}=6,3 \pm 6,3)$; oxigênio dissolvido $3,5-5,8 \mathrm{mg} . \mathrm{L}^{-1}(\bar{x}=4,6 \pm 4,5)$; turbidez 0-86 NTU ( $\left.\bar{x}=18 \pm 16\right)$; 

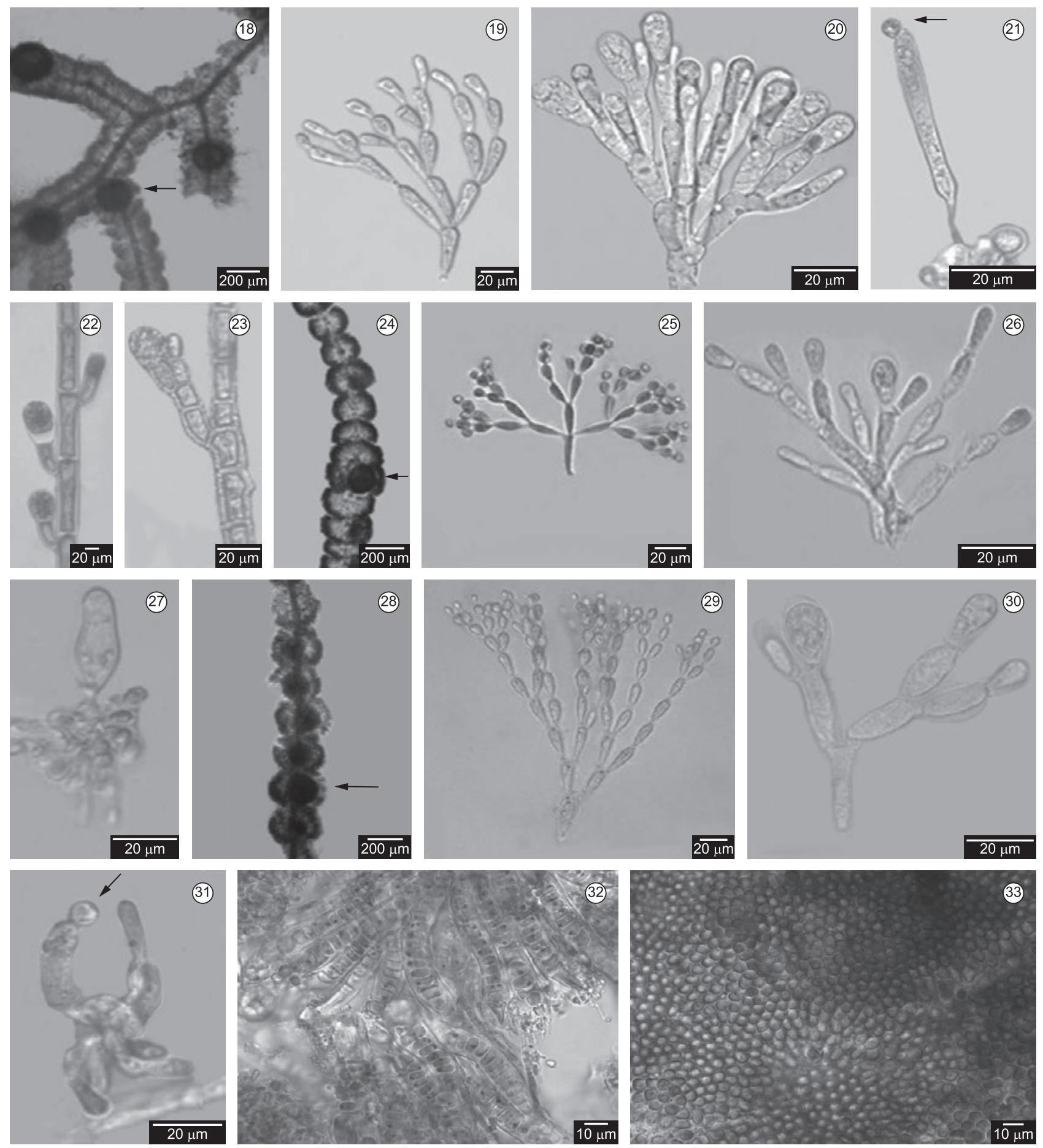

Figuras 18-33. Fotomicrografias das Rhodophyta de Unidades de Conservação da região Sul do Brasil. 18-21. Batrachospermum helminthosum. 18. Verticilo com carposporófito. 19. Fascículo primário. 20. Filamento gonimoblástico com carposporângios terminais. 21. Ramo carpogonial com carpogônio fertilizado com espermácio aderido (seta). 22. 'Chantransia' macrospora. 23. 'Chantransia' pygmaea. 24-27. Kumanoa abilii. 24. Verticilo com carposporófitos. 25. Fascículo primário. 26. Filamento gonimoblástico com carposporângios terminais. 27. Ramo carpogonial com carpogônio. 28-31. K. ambigua. 28. Verticilo com carposporófitos. 29. Fascículo primário. 30. Filamento gonimobástico com carposporângios terminais. 31. Ramo carpogonial com carpogônio fertilizado com espermácio aderido (seta). 32-33. Hildenbrandia angolensis. 32. Vista lateral das células vegetativas. 33. Vista superficial das células vegetativas. Barras $=200 \mu \mathrm{m}$, Figuras 18, 24, 28; $20 \mu \mathrm{m}$ Figuras 19-21, 22-23, 25-27, 29-31; $10 \mu \mathrm{m}$, Figuras 32-33.

Figures 18-33. Photomicrography of Rhodophyta from Conservation Units of Southern Brazil. 18-21. Batrachospermum helminthosum. 18. Whorls showing carposporophyte. 19. Primary fascicle. 20. Gonimoblastic filaments with terminal carposporangia. 21. Carpogonium-bearing branch with fertilized carpogonium with attached spermatium (arrow). 22. 'Chantransia' macrospora. 23. 'Chantransia' pygmaea. 24-27. Kumanoa abilii. 24. Whorls showing carposporophyte. 25. Primary fascicle. 26. Gonimoblastic filaments with terminal carposporangia. 27. Carpogonium-bearing branch with carpogonium. 28-31. Kumanoa ambigua . 28. Whorls showing carposporophyte. 29. Primary fascicle. 30. Gonimoblastic filaments with terminal carposporangia. 31. Carpogonium-bearing branch with fertilized carpogonium with attached spermatium (arrow). 32-33. Hildenbrandia angolensis. 32. Lateral view of the vegetative cells. 33. Surface view of the vegetative cells. Bars $=200 \mu \mathrm{m}$, Figures 18, 24, 28; $20 \mu \mathrm{m}$, Figures 19-21, 22-23, 25-27, 29-31; $10 \mu \mathrm{m}$, Figures 32-33 
velocidade da correnteza $14-107 \mathrm{~cm} \cdot \mathrm{s}^{-1}(\bar{x}=51 \pm 52)$; profundidade média $7-36 \mathrm{~cm}(\bar{x}=17 \pm 8)$.

Considerações taxonômicas: A morfometria celular das populações estudadas discordou dos valores encontrados na literatura. $\mathrm{O}$ intervalo das medidas celulares dos espécimes analisados no presente estudo são maiores do que aqueles reportados na literatura (3,0-11,7 $\mu \mathrm{m}$ comp. e 2,3-9,0 $\mu \mathrm{m}$ diâm) (Carmona-Jiménez et al. 2002, Necchi Júnior 1987b, Sheath et al. 1993a).

Além disso, os indivíduos do ponto de amostragem 27 apresentaram comprimento e diâmetro celulares maiores do que os citados na literatura para $H$. rivularis, espécie caracterizada por ter medidas maiores do que $H$. angolensis $(7,5-19,2 \mu \mathrm{m}$ comp. e 9,1-22,0 $\mu$ m diâm do presente estudo em comparação a 8,7-13,0 $\mu \mathrm{m}$ comp. e 5,2-10,2 $\mu \mathrm{m}$ diâm de $H$. rivularis reportada por Sheath et al. 1993a). Sugere-se, então, a realização de estudo revisionário desse gênero levando-se em conta dados morfológicos e moleculares para que se possa compreender melhor estas variações.

\section{Discussão}

O levantamento taxonômico das Rhodophyta de riachos de unidades de conservação da região Sul do Brasil identificou oito espécies na área estudada. Em trabalhos prévios conduzidos em várias regiões do Brasil e do mundo que abordaram a taxonomia e a distribuição ecológica de algas vermelhas de águas continentais foi observada, em regra, maior diversidade global de espécies do que no presente estudo. Necchi Júnior (1989) conduziu um levantamento taxonômico de Rhodophyta de riachos no estado de São Paulo onde foram encontrados 21 táxons. Ainda no estado de São Paulo, Necchi Júnior et al. (1999) investigaram 172 segmentos de riachos abrangendo diferentes biomas e regiões geológicas e identificaram 17 espécies. Por sua vez, Entwisle \& Kraft (1984), em um estudo com algas vermelhas realizado em mais de 200 riachos na região sudeste da Austrália, registraram 14 espécies. Por fim, Eloranta \& Kwandrans (1996) realizaram o levantamento das algas vermelhas para a Finlândia, envolvendo a análise de 60 pontos de amostragem, e reconheceram 16 espécies. A menor diversidade global observada na região Sul do Brasil em relação aos dados da literatura pode ser atribuída a uma menor variabilidade ambiental, uma vez que as amostragens foram realizadas exclusivamente em unidades de conservação. Assim, durante as amostragens não foram investigados riachos de águas duras, rios de grande porte, além de rios/riachos eutróficos e/ou com presença de impacto antrópico relevante. A ausência desta heterogeneidade de condições ambientais pode ter contribuído para uma menor riqueza de espécies de rodófitas em comparação com os estudos previamente realizados e reportados na literatura.

O gênero Batrachospermum foi o melhor representado na região de estudo, com cinco espécies identificadas. Em estudos prévios realizados no Brasil e no mundo, resultados semelhantes também foram observados (Necchi Júnior 1989, Necchi Júnior et al. 1999, Entwisle \& Kraft 1984, Eloranta \& Kwandrans 1996, Kwandrans \& Eloranta 2010, Sheath \& Cole 1992). Assim, nossos dados confirmam Skuja (1938), que aponta o gênero Batrachospermum como sendo o melhor representado em número de espécies entre as Rhodophyta de água doce.

\section{Agradecimentos}

Os autores agradecem ao $\mathrm{CNPq}$ pelas bolsas de doutorado a CKP (Proc. 141754/2007-9) e de produtividade a CCZB (Proc. 302354/2008-5) e ONJ (Proc. 303952/2009-1); a FAPESP pelo financiamento do projeto "Macroalgas lóticas do Sul do Brasil" (Proc. 2007/52608-1) e a bolsa de Iniciação Científica a TAR (Proc. 2009/18436-4); ao Instituto Chico Mendes de Conservação da Biodiversidade (ICMBio) e às Unidades de Conservação mencionadas pela autorização de coleta e apoio logístico durante os trabalhos de campo.

\section{Referências Bibliográficas}

BORY DE SAINT-VINCENT, J.B.G.M. 1808. Mémoire sur le genre Batrachospermae de la famille des Conferves. Ann. Mus. Hist. Nat. 12: 310-332.

BRANCO, C.C.Z., EMED, R.G., BRANCO, L.H.Z. \& NECCHI JÚNIOR, O. 2008. Macroalgas de riachos da Floresta Nacional de Irati, região centro-sul do estado do Paraná, sul do Brasil. Acta Bot. Bras. 22:433-447. http://dx.doi.org/10.1590/S0102-33062008000200013

BRANCO, C.C.Z., PERES, C.K., KRUPEK, R.A. \& BERTUSSO, F.R. 2009. Macroalgas de ambientes lóticos da região centro-oeste do Paraná, região Sul do Brasil. Biota Neotrop. 9:1-9. http://dx.doi.org/10.1590/ S1676-06032009000200022

CARMONA-JIMÉNEZ, J., MONTEJANO, G. \& GONZÁLEZGONZÁLEZ, J. 2002. Taxonomía y distribución de Hildenbrandia Nardo (Hildenbrandiales, Rhodophyta) de agua dulce en la región central del Mexico. Hidrobiológica 12: 7-14.

ELORANTA, P. \& KWANDRANS, J. 1996. Distribution and ecology of freshwater red algae (Rhodophyta) in some central Finnish rivers. Nord. J. Bot. 16:107-117. http://dx.doi.org/10.1111/j.1756-1051.1996.tb00220.x

ENTWISLE, T.J. \& KRAFT, G.T. 1984. Survey of freshwater red algae (Rhodophyta) of South-eastern Australia. Aust. J. Mar. Freshwat. Res. 35:213-259. http://dx.doi.org/10.1071/MF9840213

ENTWISLE, T.J., VIS, M.L., CHIASSON, W.B., NECCHI JÚNIOR, O. \& SHERWOOD, A.R. 2009. Systematics of the Batrachospermales (Rhodophyta) - A synthesis. J. Phycol. 45:704-715. http://dx.doi. org/10.1111/j.1529-8817.2009.00686.x

GRAHAM, L.E. \& WILCOX, L.W. 2000. Algae. Prentice-Hall, Upper Saddle River, New Jersey, USA.

HANYUDA, T., SUZAWA, Y., SUZAWA, T., ARAI, S., SATO, H., UEDA, K. \& KUMANO, S. 2004. Biogeography and taxonomy of Batrachospermum helminthosum Bory (Batrachospermales, Rhodophyta) in Japan inferred from $r b c \mathrm{~L}$ gene sequences. J. Phycol. 40:581-8. http:// dx.doi.org/10.1111/j.1529-8817.2004.03159.x

HARVEY, W.H. 1841. A manual of the British algae: containing generic and specific descriptions of the known British species of sea-weeds and of Confervae both marine and freshwater. John Van Voorst, London. p.i-v-vii, 1-229.

HOLMGREN, P.K. \& HOLMGREN, N.H. 1998 [continuously updated]. Index Herbariorum: a global directory of public herbaria and associated staff. New York Botanical Garden's Virtual Herbarium. http://sweetgum. nybg.org/ih/

JOHANSSON, C. 1982. Attached algal vegetation in running waters of Jämtland. Sweden. Acta Phytogeogr. Suec. 71:1-83.

KRUPEK, R.A., BRANCO, C.C.Z. \& PERES, C.K. 2008. Levantamento florístico das comunidades de macroalgas da bacia do rio das Pedras, região centro-sul do Estado do Paraná, Sul do Brasil. Hoehnea 35:25-44.

KUMANO, S. 1993. Taxonomy of the family Batrachospermaceae (Batrachospermales, Rhodophyta). Jpn. J. Phycol. 41:253-72.

KUMANO, S. 2002. Freshwater Red Algae of the World. Biopress, Ltd. Bristol, London.

KUMANO, S. \& NECCHI JÚNIOR, O. 1990. Batrachospermum macrosporum Montagne from South America. Jpn. J. Phycol. 38:119-23.

KWANDRANS, J. \& ELORANTA, P. 2010. Diversity of freshwater red algae in Europe. Int. J. Oceanogr. Hydrobiol. 39:161-169. http://dx.doi. org/10.2478/v10009-010-0015-7 
KYLIN, H. 1912. Studien über die Schwedischen Arten der Gattungen Batrachospermum Roth und Sirodotia nov. gen. Nova Acta Regiae Soc. Sci. Ups. Ser. IV, 3:1-40.

NECCHI JÚNIOR, O. 1986. Studies on the freshwater Rhodophyta of Brazil - 4: four new species of Batrachospermum (Section Contorta) from the Southern State of São Paulo. Rev. Bras. Biol. 46:517-525.

NECCHI JÚNIOR, O. 1987a. Studies on the freshwater Rhodophyta of Brazil - 3: Batrachospermum brasiliense sp. nov. from the state of São Paulo, southern Brazil. Rev. Bras. Biol. 47:441-446.

NECCHI JÚNIOR, O. 1987b. Estudos sobre as Rhodophyta de águas continentais do Brasil - 6: ocorrência de Hildenbrandia rivularis (Liebmann) J. Agardh nos estados do Rio de Janeiro e São Paulo. Neritica 2:147-152.

NECCHI JÚNIOR, O. 1989. Rhodophyta de água doce do Estado de São Paulo: levantamento taxonômico. Bolm. Bot. Univ. S. Paulo 11:11-69.

NECCHI JÚNIOR, O. 1990a. Revision of the genus Batrachospermum Roth (Rhodophyta, Batrachospermales) in Brazil. Bibl. Phycol. 84:1-201.

NECCHI JÚNIOR, O. 1990b. Evaluation of morphologic taxonomic characters in Brazilian species of Batrachospermum (Rhodophyta, Batrachospermales). Rev. Bras. Biol. 50:643-651.

NECCHI JÚNIOR, O. 1991. The section Sirodotia of Batrachospermum (Rhodophyta, Batrachospermaceae) in Brazil. Algol. Stud. 62:17-30.

NECCHI JÚNIOR, O. 1993. Distribution and seasonal dynamics of Rhodophyta in the Preto River Basin, southeastern Brazil. Hydrobiologia 250:81-90. http://dx.doi.org/10.1007/BF00008229

NECCHI JÚNIOR, O., BRANCO, C.C.Z. \& BRANCO, L.H.Z. 1999. Distribution of Rhodophyta in streams from São Paulo State, southeastern Brazil. Arch. Hydrobiol. 147:73-89.

NECCHI JÚNIOR, O., OLIVEIRA, M.C. \& SALLES, P. 2010a Molecular systematics of Thorea (Rhodophyta, Thoreales) species in Brazil. Rev. Bras. Bot. 33:227-235. http://dx.doi.org/10.1590/S010084042010000200004

NECCHI JÚNIOR, O., VIS, M.L. \& OLIVEIRA, M.C. 2007. Phylogenetic relationship of Sirodotia species (Batrachospermales, Rhodophyta) in North and South America. Cryptogam. Algol. 27:117-127.

NECCHI JÚNIOR, O., VIS, M.L. \& OLIVEIRA, M.C. 2010b. Phylogenetic relationships in Kumanoa (Batrachospermales, Rhodophyta) species in Brazil with the proposal of Kumanoa amazonensis sp. nov. Phycologia 49:97-103. http://dx.doi.org/10.2216/09-24.1

NECCHI JÚNIOR, O. \& ZUCCHI, M.R. 1997. Audouinella macrospora (Acrochaetiaceae, Rhodophyta) is the 'Chantransia' stage of Batrachospermum (Batrachospermaceae). Phycologia 36:220-224. http://dx.doi.org/10.2216/i0031-8884-36-3-220.1

PERES, C.K., BRANCO, C.C.Z. \& KRUPEK, R.A. 2008. Macroalgas de riachos da Serra da Prata, leste do estado do Paraná, Sul do Brasil. Acta Bot. Bras. 22:333-344. http://dx.doi.org/10.1590/S010233062008000200004
PUESCHEL, C.M., SAUNDERS, G.W. \& WEST, J.A. 2000. Affinities of the freshwater red alga Audouinella macrospora (Florideophyceae, Rhodophyta) and related forms based on SSU rDNA gene sequence and pit plug ultrastructure. J. Phycol. 36:433-439. http://dx.doi.org/10.1046/ j.1529-8817.2000.99173.x

SHEATH, R.G. \& COLE, K.M. 1992. Biogeography of stream macroalgae in North America. J. Phycol. 28:448-460. http://dx.doi.org/10.1111/j.00223646.1992.00448.x

SHEATH, R.G., KACZMARCZYK, D. \& COLE, K.M. 1993a. Distribution and systematics of freshwater Hildenbrandia (Hildenbrandiales, Rhodophyta) in North America. Eur. J. Phycol. 28:115-121. http://dx.doi. org/10.1080/09670269300650191

SHEATH, R.G., VIS, M.L. \& COLE, K.M. 1992. Distribution and systematics of Batrachospermum (Batrachospermales, Rhodophyta) in North America. 1. Section Contorta. J. Phycol. 28:237-246.

SHEATH, R.G., VIS, M.L. \& COLE, K.M. 1993b. Distribution and systematics of Batrachospermum (Batrachospermales, Rhodophyta) in North America. 3. Section Setacea. J. Phycol. 29:720-726.

SHEATH, R.G., VIS, M.L. \& COLE, K.M. 1994a. Distribution and systematics of Batrachospermum (Batrachospermales, Rhodophyta) in North America. 4. Section Virescencia. J. Phycol. 30:108-117.

SHEATH, R.G., VIS, M.L. \& COLE, K.M. 1994b. Distribution and systematics of Batrachospermum (Batrachospermales, Rhodophyta) in North America. 5. Section Aristata. J. Phycol. 33:404-414

SHEATH, R.G., VIS, M.L. \& COLE, K.M. 1994c. Distribution and systematics of Batrachospermum (Batrachospermales, Rhodophyta) in North America. 6. Section Turfosa. J. Phycol. 30:872-884.

SHEATH, R.G., VIS, M.L. \& COLE, K.M. 1995. Distribution and systematics of Batrachospermum (Batrachospermales, Rhodophyta) in North America. 7. Section Hybrida. Phycologia 34:431-438. http://dx.doi. org/10.2216/i0031-8884-34-5-431.1

SKUJA, H. 1938. Comments on freshwater Rhodophyceae. Botanical Review. Rev. 4:665-676.

VIS, M.L., ENTWISLE, T.J., WEST, J.A. \& OTT, F.D. 2006. Ptilothamnion richardsii (Rhodophyta) is a 'Chantransia' stage of Batrachospermum. Eur. J. Phycol. 41:125-30. http://dx.doi.org/10.1080/09670260500418504

VIS, M.L., SHEATH, R.G. \& ENTWISLE, T.J. 1995. Morphometric analysis of Batrachospermum section Batrachospermum (Batrachospermales, Rhodophyta) type specimens. Eur. J. Phycol. 30:35-55. http://dx.doi. org/10.1080/09670269500650791

WEST, W. \& WEST, G.S. 1897. Welwitsch's African freshwater algae. J. Bot. (Brit, and For.) 35:1-7.

WITTROCK, V.B. \& NORDSTEDT, C.F.O. 1883. Algae aquae dulcis exsiccatae praecipue scandinavicae quas adjectis algis marinis chlorophyllaceis et phycochromaceis. O.L. Svanbäcks Boktryckeri Aktiebolac., Holmiae, fasc. 11, exsic. 501-550.

Recebido em 12/07/2011 Versão reformulada recebida em 14/09/2011 Publicado em 16/09/2011 